\title{
A meta-analysis of ursodeoxycholic acid therapy versus combination therapy with corticosteroids for PBC-AIH-overlap syndrome: evidence from 97 monotherapy and 117 combinations
}

\author{
Huawei Zhang ${ }^{1,2}$, Sainan Li ${ }^{1}$, Jing Yang ${ }^{1}$, Yuanyuan Zheng ${ }^{1}$, Jianrong Wang ${ }^{1,3}$, Wenxia Lu ${ }^{1,3}$, Yuqing Zhou ${ }^{1,2}$, \\ Qin Yin ${ }^{1,2}$, Rong Zhu ${ }^{1,3}$, Chuanyong Guo ${ }^{1}$ \\ ${ }^{1}$ Department of Gastroenterology, Shanghai Tenth People's Hospital, Tongji University School of Medicine, Shanghai, China \\ ${ }^{2}$ The First affiliated Hospital of Soochow University, Suzhou, China \\ ${ }^{3}$ The First Clinical Medical College of Nanjing Medical University, Nanjing, China
}

Prz Gastroenterol 2015; 10 (3): 148-155 DOI: $10.5114 /$ pg.2015.51187

Key words: meta-analysis, ursodeoxycholic acid, corticosteroids, combination therapy, overlap syndrome.

Address for correspondence: Prof. Chuanyong Guo MD, PhD, Department of Gastroenterology, Shanghai Tenth People's Hospital, Tongji University School of Medicine, 200072 Shanghai, China, phone: +8615232345674 , e-mail: guochuanyong@hotmail.com

\begin{abstract}
In this study, a meta-analysis of randomised controlled trials that compared ursodeoxycholic acid (UDCA) monotherapy with therapies combining UDCA and corticosteroids was performed. We found that combination therapy with UDCA and corticosteroids was more effective than UDCA monotherapy for primary biliary cirrhosis-autoimmune hepatitis-overlap syndrome.
\end{abstract}

\section{Introduction}

Autoimmune liver disease (ALD) is a group of diseases of unknown aetiology and immune-mediated liver diseases, including autoimmune hepatitis $(\mathrm{AlH})$, primary biliary cirrhosis (PBC), and primary sclerosing cholangitis [1]. Some patients display the characteristics of two diseases based on clinical, biochemical, immunological, or histological analyses, at different stages during the course of their disease. This is called "overlap syndrome", among which primary biliary cirrhosis-autoimmune hepatitis (PBC-AIH) is the most common [2]. However, because of its low incidence and the lack of uniform diagnostic criteria, the exact pathogenesis of PBC-AIH remains unclear. The incidence of PBC-AlH is reported to be between $2 \%$ and $20 \%$, based on different diagnostic criteria [3-5]. Because there have been few mechanised large-scale randomised double-blind controlled clinical trials or prospective controlled studies of PBC-AIH, progress in the treatment of this disease is relatively slow. Corticosteroids have had positive effects on AIH [6], and ursodeoxycholic acid (UDCA) can effectively improve $\mathrm{PBC}$-associated cholestasis, prolong sur- vival, and delay histological progression [7, 8]. In some studies of PBC-AIH, the results of a therapy combining UDCA and corticosteroids were encouraging $[9,10]$, but there have been few local studies [11]. Last year, a meta-analysis of Zhang et al. [12] showed that combination therapy was more effective, but the number of studies included in this analysis was small.

\section{Aim}

Therefore, we further conducted this meta-analysis to explore the efficacy and safety of UDCA combined with corticosteroid therapy for $\mathrm{PBC}-\mathrm{AlH}$, hoping to provide strong supporting evidence for the use of this treatment in clinical practice.

\section{Material and methods}

Determining the research standards

Objectives of the study

The PBC-AlH was strictly defined as the association of PBC and $\mathrm{AlH}$. The presence of at least 2 of the $3 \mathrm{ac}-$ cepted criteria was required for the diagnosis of each disease [13]. The criteria for PBC are: (1) alkaline phospha- 
tase (AP) levels at least two times higher than the upper limit of normal (ULN) or $\gamma$-glutamyl transpeptidase (GGT) levels at least five times higher than the ULN; (2) a positive test for anti-mitochondrial antibodies; and (3) a liver biopsy specimen showing florid bile duct lesions. The criteria for AlH are: (1) alanine aminotransferase (ALT) levels at least five times higher than the ULN; (2) serum immunoglobulin $\mathrm{G}(\operatorname{lgG})$ levels at least two times higher than the ULN, or a positive test for anti-smooth-muscle antibodies; and (3) a liver biopsy showing moderate or severe periportal or periseptal piecemeal lymphocytic necrosis. Other liver diseases were excluded, including hepatitis B, hepatitis C, alcoholic cirrhosis, cryptogenic cirrhosis, and primary biliary sclerosis.

\section{Inclusion criteria}

(1) A randomised controlled trial of UDCA monotherapy and UDCA combined with corticosteroids, whether or not it was blinded in design, and any type of publication; (2) the diagnostic criteria for PBC-AlH in the study met those in the literature; (3) the establishment of a parallel designed randomised controlled trial (RCT); (4) none of the test subjects had received prior treatment with other drugs; (5) the UDCA and corticosteroids dose ranges were not limited.

\section{Exclusion criteria}

(1) Any uncontrolled trials, nonrandomised controlled trials, and quasi-randomised controlled trials; (2) randomised controlled trials of UDCA combined with any other drugs; (3) randomised controlled trials of UDCA versus a placebo; (4) animal experiments and studies of cells or tissues.

\section{Study criteria}

The relevant studies were identified and selected by searching the databases PubMed, Cochrane Library,
EMBASE, CINAHL, and the Science Citation Index (updated to March 2014) [14] with the search terms "ursodeoxycholic acid", "corticosteroids", "combination therapy”, "PBC-AlH”, "overlap syndrome”, "randomised controlled trial", and "meta-analysis". We also performed a full manual search of all review articles, retrieved original studies, and abstracts.

\section{Data extraction}

The data were independently extracted from each study by two researchers (Huawei Zhang and Sainan $\mathrm{Li}$ ), and any disagreement was resolved by consensus. The following data were extracted from each article included: the name of the first author, year of publication, number of patients, daily dose of oral therapy, duration of treatment, method used to deal with missing data, liver biochemistry (AP, ALT, aspartate aminotransferase (AST), GGT, IgG, IgM), symptoms, liver histology, death, liver transplantation, death and/or transplantation, and adverse events.

\section{Methodological quality}

The methodological quality of the studies included in the meta-analysis was scored with the Jadad composite scale (Table I) $[15,16]$. This is a 5 -point quality scale, with low-quality studies having a score $\leq 2$ and high-quality studies a score $\geq 3$. Methodological quality was independently assessed by two authors of the study. Each study was given an overall quality score based on the criteria described above, which was then used to rank the studies. Any disagreement was resolved by consensus.

\section{Statistical analysis}

All analyses were performed with RevMan5.2 (The Nordic Cochrane Centre, The Cochrane Collaboration, 2012). The odds ratio (OR) for each clinical event is presented with its $95 \%$ confidence interval $(\mathrm{Cl})$. We test-

Table I. Criteria used to grade the quality of RCTs: the Jadad scores

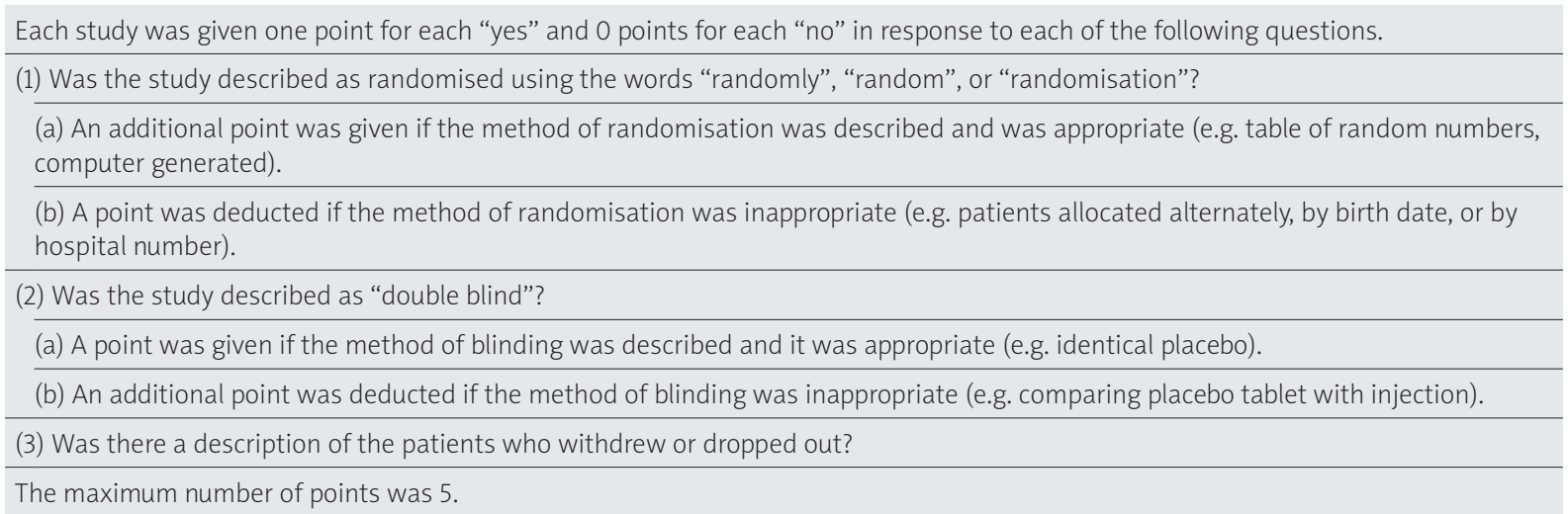


ed heterogeneity using the $\chi^{2}$ test and the $r^{2}$ test, and a $p$ value $<0.10$ or an $R^{2}$ value $>50 \%$ was considered to indicate substantial heterogeneity. A fixed-effects model was used when the heterogeneity test had a $p$ value $>0.10$ or an $R^{2}$ value $<50 \%$; otherwise, a random-effects model was used. We also constructed funnel plots to evaluate the presence of publication bias.

\section{Results}

\section{Descriptive and qualitative assessments}

After we had excluded reviews, case reports, repeated studies, and research whose purpose was unrelated to the evaluation system or inconsistent with the literature, we finally selected eight RCTs from 1578 studies [17-24].

These studies involved 214 patients: 97 were randomised to the UDCA monotherapy groups and 117 to the combination therapy (UDCA and corticosteroids) groups. The mean ages ranged from 44 to 55 years and the mean follow-up periods ranged from 10 to
90 months. The daily dose of UDCA ranged from 10 to $15 \mathrm{mg} / \mathrm{kg}$, and the daily dose of corticosteroids ranged from 0.5 to $1 \mathrm{mg} / \mathrm{kg}$ (only Ozaslan [2014] used a dose of 30-60 mg/day). The baseline characteristics of the eight trials are listed in Table II. The descriptive results are shown in Table III.

\section{Quality assessment of the studies included}

The methodological quality scores ranged from 2 to 5 (Table IV). Six of the eight randomised studies adequately described the way in which they were randomised. All the studies used a double-blind method, and five provided specific descriptions of the blinding used. Six studies described the withdrawals and lost cases. Three studies described allocation concealment, whereas five had no such description. Overall, the Jadad scores of all the RCTs were $\geq 3$ points, and so were considered high-quality research.

Table II. Baseline characteristics of the trials included in the meta-analysis

\begin{tabular}{|c|c|c|c|c|c|c|c|}
\hline Authors, year & $\begin{array}{l}\text { Mean } \\
\text { age } \\
\text { [years] }\end{array}$ & $\begin{array}{c}\text { Monotherapy } \\
\text { (n) }\end{array}$ & $\begin{array}{l}\text { Combination } \\
\text { therapy } \\
(n)\end{array}$ & $\begin{array}{l}\text { UDCA dose } \\
\text { [mg/kg } \\
\text { day }]\end{array}$ & $\begin{array}{c}\text { Immunosuppression } \\
\text { dose } \\
{[\mathrm{mg} / \mathrm{kg} \cdot \text { day }]}\end{array}$ & $\begin{array}{l}\text { Duration } \\
\text { of treatment } \\
\text { [months] }\end{array}$ & $\begin{array}{c}\text { Publication } \\
\text { type }\end{array}$ \\
\hline Chazouilleres, 1998 [17] & 50 & 5 & 6 & $13-15$ & 0.5 & 23 & Full text \\
\hline Gunsar, 2002 [18] & 44 & 13 & 7 & 13 & 0.5 & 28 & Full text \\
\hline Chazouilleres, 2006 [10] & 41 & 11 & 6 & $13-15$ & 0.5 & 90 & Full text \\
\hline Heurgue, 2007 [19] & 44 & 9 & 4 & $11-14.7$ & $0.5-1$ & 60 & Full text \\
\hline Ozaslan, 2010 [20] & 44 & 3 & 9 & $13-15$ & 0.5 & 31 & Full text \\
\hline Tanaka, 2011 [21] & 54 & 15 & 10 & 10 & 0.5 & 73 & Full text \\
\hline Zhu, 2011 [22] & 50 & 11 & 8 & $13-15$ & $0.5-1$ & 10 & Full text \\
\hline Ozaslan, 2014 [23] & 48 & 30 & 67 & $13-15$ & $30-60[\mathrm{mg} / \mathrm{day}]$ & 66 & Full text \\
\hline
\end{tabular}

Table III. Descriptive results of the randomised trials

\begin{tabular}{|c|c|c|c|c|c|c|c|c|c|c|c|c|}
\hline \multirow[t]{2}{*}{ Authors } & \multicolumn{2}{|c|}{$\begin{array}{l}\text { Symptoms } \\
\text { improved }\end{array}$} & \multicolumn{2}{|c|}{$\begin{array}{l}\text { Liver- } \\
\text { biochemistry } \\
\text { improved }\end{array}$} & \multicolumn{2}{|c|}{$\begin{array}{l}\text { Histology } \\
\text { progression }\end{array}$} & \multicolumn{2}{|c|}{ Death } & \multicolumn{2}{|c|}{$\begin{array}{c}\text { Death or liver } \\
\text { transplantation U }\end{array}$} & \multicolumn{2}{|c|}{$\begin{array}{l}\text { Adverse } \\
\text { events }\end{array}$} \\
\hline & UDCA & COM & UDCA & COM & UDCA & COM & UDCA & COM & UDCA & COM & UDCA & COM \\
\hline Chazouilleres [17] & $2 / 5$ & $3 / 6$ & $2 / 5$ & $6 / 6$ & $3 / 5$ & $0 / 2$ & $1 / 5$ & $0 / 6$ & $1 / 5$ & $0 / 6$ & $1 / 5$ & $2 / 6$ \\
\hline Gunsar [18] & $1 / 16$ & $0 / 7$ & $8 / 16$ & $7 / 7$ & $5 / 8$ & $1 / 7$ & $0 / 16$ & $1 / 7$ & $0 / 16$ & $1 / 7$ & $1 / 16$ & $0 / 7$ \\
\hline Chazouilleres [10] & $3 / 11$ & $0 / 6$ & $4 / 11$ & $6 / 6$ & $4 / 8$ & $0 / 4$ & $N R$ & $N R$ & $0 / 11$ & $1 / 6$ & NR & NR \\
\hline Heurgue [19] & $1 / 6$ & $1 / 4$ & $3 / 6$ & $3 / 4$ & $3 / 6$ & $1 / 4$ & NR & NR & $0 / 6$ & $0 / 4$ & NR & NR \\
\hline Ozaslan [20] & $3 / 3$ & $3 / 9$ & $3 / 3$ & $3 / 9$ & $0 / 3$ & $6 / 9$ & $0 / 3$ & $2 / 9$ & $0 / 3$ & $3 / 9$ & NR & NR \\
\hline Tanaka [21] & $3 / 15$ & $1 / 10$ & $8 / 15$ & $10 / 10$ & $7 / 15$ & $0 / 10$ & $0 / 15$ & $1 / 10$ & $0 / 15$ & $1 / 10$ & NR & NR \\
\hline Zhu [22] & $0 / 11$ & $0 / 8$ & $6 / 11$ & $8 / 8$ & $3 / 3$ & $0 / 3$ & NR & NR & $0 / 11$ & $0 / 8$ & $2 / 11$ & $1 / 8$ \\
\hline Ozaslan [23] & $0 / 30$ & $0 / 67$ & $19 / 30$ & $56 / 67$ & $18 / 23$ & $12 / 14$ & $0 / 30$ & $5 / 67$ & $0 / 30$ & $9 / 67$ & NR & NR \\
\hline
\end{tabular}

UDCA - Monotherapy with ursodeoxycholic acid, COM - combination therapy with UDCA and corticosteroids, NR - not reported. 
Table IV. Jadad quality scores of the trials included in the meta-analysis

\begin{tabular}{lcccc} 
Study & Randomisation method & Double blinding & Withdrawals dropouts & Total \\
\hline Chazouilleres, 1998 [17] & 2 & 2 & 1 & 5 \\
\hline Gunsar, 2002 [18] & 1 & 2 & 1 & 4 \\
\hline Chazouilleres, 2006 [10] & 2 & 2 & 1 & 5 \\
\hline Heurgue, 2007 [19] & 2 & 1 & 1 & 4 \\
\hline Ozaslan, 2010 [20] & 1 & 2 & 0 & 4 \\
\hline Tanaka, 2011 [21] & 2 & 1 & 1 & 3 \\
\hline Zhu, 2011 [22] & 2 & 2 & 1 & 5 \\
\hline Ozaslan, 2014 [23] & 2 & 1 & 1 & 4
\end{tabular}

\section{Meta-analysis}

\section{Pruritus and jaundice}

Eight trials [10, 17-23], including 214 patients, reported data regarding the endpoints of pruritus and jaundice. The symptoms improved in 13 of 97 patients in the monotherapy groups and in eight of 117 patients in the combination therapy groups. There was no significant heterogeneity $\left(p=0.68, I^{2}=0 \%\right)$, and there were no significant differences between the groups $(\mathrm{OR}=2.12$, $95 \% \mathrm{Cl}: 0.72-6.18, p=0.17$; Figure 1 ).

\section{ALT and AP levels}

Eight trials, including 214 patients, reported data regarding the endpoints of ALT and AP levels. The symptoms improved in 53 of 97 patients in the monotherapy groups and in 99 of 117 patients in the combination therapy groups. There was no significant heterogeneity $\left(p=0.16, l^{2}=33 \%\right)$, but there were significant differenc- es between the groups ( $\mathrm{OR}=0.25,95 \% \mathrm{Cl}: 0.13-0.48$, $p<0.0001$; Figure 2).

\section{Histological progression}

Of the 214 patients (eight trials) who underwent second biopsies, the histology declined in 43 of 71 patients in the monotherapy groups and in 20 of 53 patients in the combination therapy groups. There was no significant heterogeneity $\left(p=0.08, R^{2}=34 \%\right)$, but there were significant differences between the groups $(\mathrm{OR}=2.57$, $95 \% \mathrm{Cl}: 1.19-5.52, p=0.02$; Figure 3 ).

\section{Death or liver transplantation}

Seven trials, including 214 patients, reported data for the endpoint death or liver transplantation. Death or liver transplantation occurred in one of 97 patients in the monotherapy groups and in 15 of 117 patients in the combination therapy groups. There was no significant heterogeneity $\left(p=0.66, l^{2}=0 \%\right)$, but there were

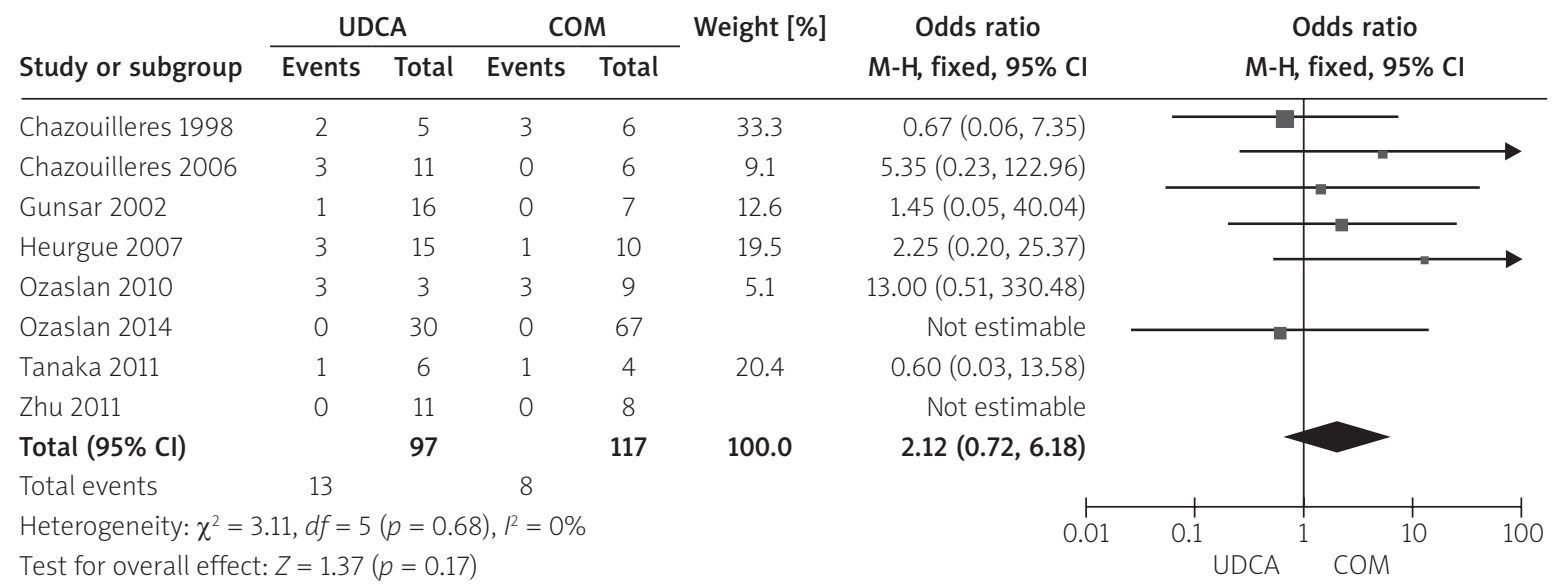

Figure 1. Effects of monotherapy versus combination therapy on pruritus and jaundice in patients with PBC-AIH 


\begin{tabular}{|c|c|c|c|c|c|c|c|c|c|}
\hline \multirow[b]{2}{*}{ Study or subgroup } & \multicolumn{2}{|c|}{ UDCA } & \multicolumn{2}{|c|}{ COM } & \multirow[t]{2}{*}{ Weight [\%] } & \multirow{2}{*}{$\begin{array}{c}\text { Odds ratio } \\
\mathrm{M}-\mathrm{H} \text {, fixed, } 95 \% \mathrm{Cl}\end{array}$} & \multirow{2}{*}{\multicolumn{2}{|c|}{$\begin{array}{c}\text { Odds ratio } \\
\mathrm{M}-\mathrm{H} \text {, fixed, } 95 \% \mathrm{Cl}\end{array}$}} & \\
\hline & Events & Total & Events & Total & & & & & \\
\hline Chazouilleres 1998 & 2 & 5 & 6 & 6 & 9.0 & $0.05(0.00,1.49)$ & & & \\
\hline Chazouilleres 2006 & 4 & 11 & 6 & 6 & 13.2 & $0.05(0.00,1.03)$ & & & \\
\hline Gunsar 2002 & 8 & 16 & 7 & 7 & 13.2 & $0.07(0.00,1.36)$ & & & \\
\hline Heurgue 2007 & 8 & 15 & 10 & 10 & 15.0 & $0.05(0.00,1.09)$ & & & \\
\hline Ozaslan 2010 & 3 & 3 & 3 & 9 & 0.6 & $13.00(0.51,330.48)$ & & & \\
\hline Ozaslan 2014 & 19 & 30 & 56 & 67 & 32.8 & $0.34(0.13,0.91)$ & & & \\
\hline Tanaka 2011 & 3 & 6 & 3 & 4 & 4.6 & $0.33(0.02,5.33)$ & & - & \\
\hline Zhu 2011 & 6 & 11 & 8 & 8 & 11.5 & $0.07(0.00,1.50)$ & & & \\
\hline Total $(95 \% \mathrm{Cl})$ & & 97 & & 117 & 100.0 & $0.25(0.13,0.48)$ & & & \\
\hline Total events & 53 & & 99 & & & & & & \\
\hline \multicolumn{5}{|c|}{ Heterogeneity: $\chi^{2}=10.49, d f=7(p=0.16), I^{2}=33 \%$} & & 0. & UDCA $^{1}$ & $\mathrm{com}^{10}$ & 100 \\
\hline
\end{tabular}

Figure 2. Biochemical parameters of patients treated with monotherapy versus combination therapy for PBC-AlH

\begin{tabular}{|c|c|c|c|c|c|c|c|c|}
\hline \multirow{3}{*}{$\frac{\text { Study or subgroup }}{\text { Chazouilleres } 1998}$} & \multicolumn{2}{|c|}{ UDCA } & \multicolumn{2}{|c|}{ COM } & \multirow[t]{2}{*}{ Weight [\%] } & \multirow{2}{*}{$\begin{array}{c}\text { Odds ratio } \\
\mathrm{M}-\mathrm{H} \text {, fixed, } 95 \% \mathrm{Cl}\end{array}$} & \multirow{2}{*}{\multicolumn{2}{|c|}{$\begin{array}{c}\text { Odds ratio } \\
M-\mathrm{H} \text {, fixed, } 95 \% \mathrm{Cl}\end{array}$}} \\
\hline & \multirow{2}{*}{$\frac{\text { Events }}{3}$} & \multirow{2}{*}{$\begin{array}{c}\text { Total } \\
5\end{array}$} & \multirow{2}{*}{$\begin{array}{c}\text { Events } \\
0\end{array}$} & \multirow{2}{*}{$\begin{array}{c}\text { Total } \\
2\end{array}$} & & & & \\
\hline & & & & & 3.3 & $7.00(0.22,218.95)$ & & \\
\hline Chazouilleres 2006 & 4 & 8 & 0 & 4 & 3.8 & $9.00(0.37,220.93)$ & & \\
\hline Gunsar 2002 & 5 & 8 & 1 & 7 & 4.7 & $10.00(0.78,128.77)$ & & \\
\hline Heurgue 2007 & 3 & 6 & 1 & 4 & 7.1 & $3.00(0.19,47.96)$ & & \\
\hline Ozaslan 2010 & 0 & 3 & 6 & 9 & 38.4 & $0.08(0.00,1.96)$ & - & \\
\hline Ozaslan 2014 & 18 & 23 & 12 & 14 & 38.3 & $0.60(0.10,3.61)$ & & \\
\hline Tanaka 2011 & 7 & 15 & 0 & 10 & 3.7 & $18.53(0.92,372.97)$ & & \\
\hline Zhu 2011 & 3 & 3 & 0 & 3 & 0.7 & $49.00(0.74,3236.99)$ & & \\
\hline Total $(95 \% \mathrm{Cl})$ & & 71 & & 53 & 100.0 & $2.57(1.19,5.52)$ & & \\
\hline Total events & 43 & & 20 & & & & & \\
\hline $\begin{array}{l}\text { Heterogeneity: } \chi^{2}= \\
\text { Test for overall effec }\end{array}$ & $\begin{array}{l}62, d f= \\
Z=2.41\end{array}$ & $\begin{array}{l}(p=0 . \\
b=0.02\end{array}$ & ),$R^{2}=$ & & & 0.0 & $\begin{array}{l}0.1 \\
\text { UDCA }\end{array}$ & $\operatorname{com}^{10}$ \\
\hline
\end{tabular}

Figure 3. Histological progression in patients treated with monotherapy or combination therapy for PBC-AlH

significant differences between the groups $(\mathrm{OR}=0.26$, 95\% Cl: 0.08-0.83, $p=0.02$; Figure 4).

\section{Adverse events}

Three trials, including 53 patients, reported data regarding endpoint adverse events. Adverse events were recorded in four of 32 patients in the monotherapy groups and in three of 21 patients in the combination therapy groups. There was no significant heterogeneity ( $p=0.82, p^{2}=0 \%$ ), and there were no significant differences between the groups (OR $=1.03,95 \% \mathrm{Cl}$ : 0.21-5.01, $p=0.97 ;$ Figure 5)

\section{Sensitivity analysis}

Jadad scores were used in this study to assess the research quality. All eight studies had scores $\geq 3$ points, and were thus considered high-quality research. Therefore, there was no need for a further sensitivity analysis.

\section{Publication bias}

Figure 6 shows the funnel plots of the meta-analysis. The funnel plots for clinical events show slight asymmetry, suggesting possible publication bias.

\section{Discussion}

In ALD, AlH is treated with corticosteroids therapy, with commonly used prednisone or prednisolone, and some non-responders or the dose may be adjusted as optional replacement therapy: cyclosporine, cyclophosphamide, budesonide, etc. [24, 25]. Corticosteroids have no significant effect on PBC when used to treat cholestatic disease, while they may increase the degree of osteoporosis in patients. The treatment for PBC is UDCA, which not only improves the indicators of cholestasis, but also significantly reduces transaminase levels [26]. Ursodeoxycholic acid is also commonly used to treat patients with $\mathrm{AlH}$. Because overlap syndrome displays the 


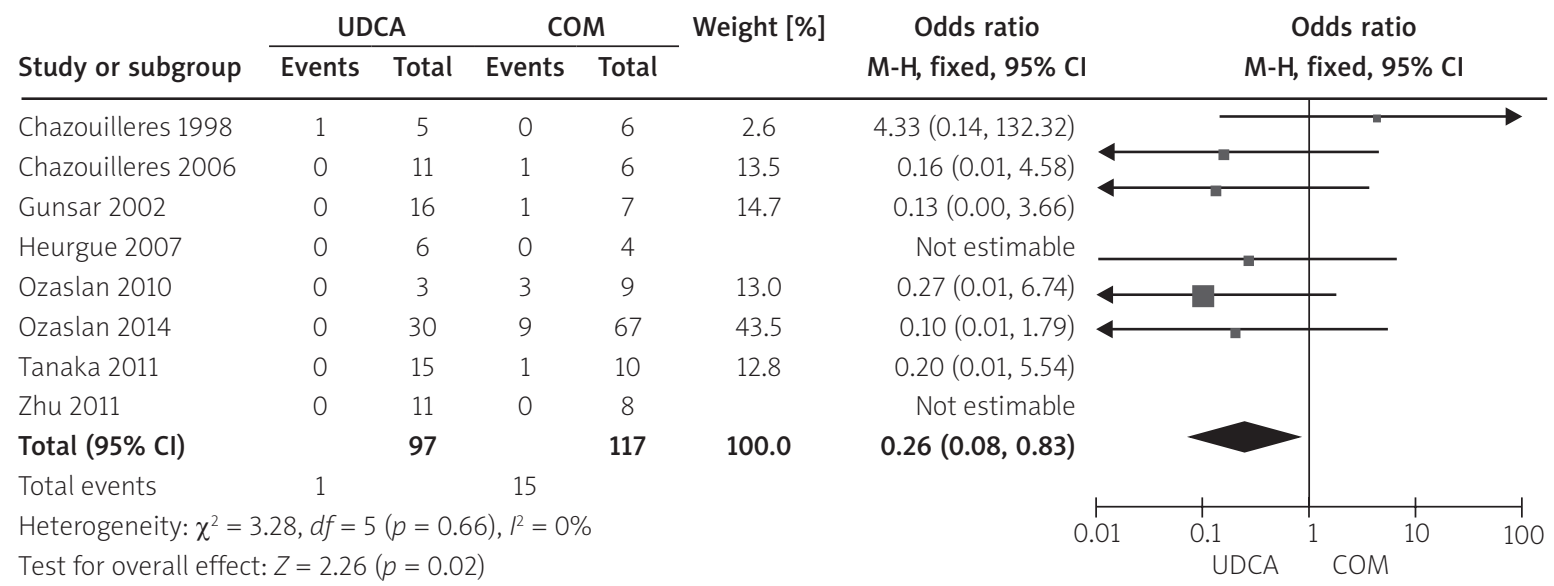

Figure 4. Death or liver transplantation in patients treated with monotherapy versus combination therapy for PBC-AIH

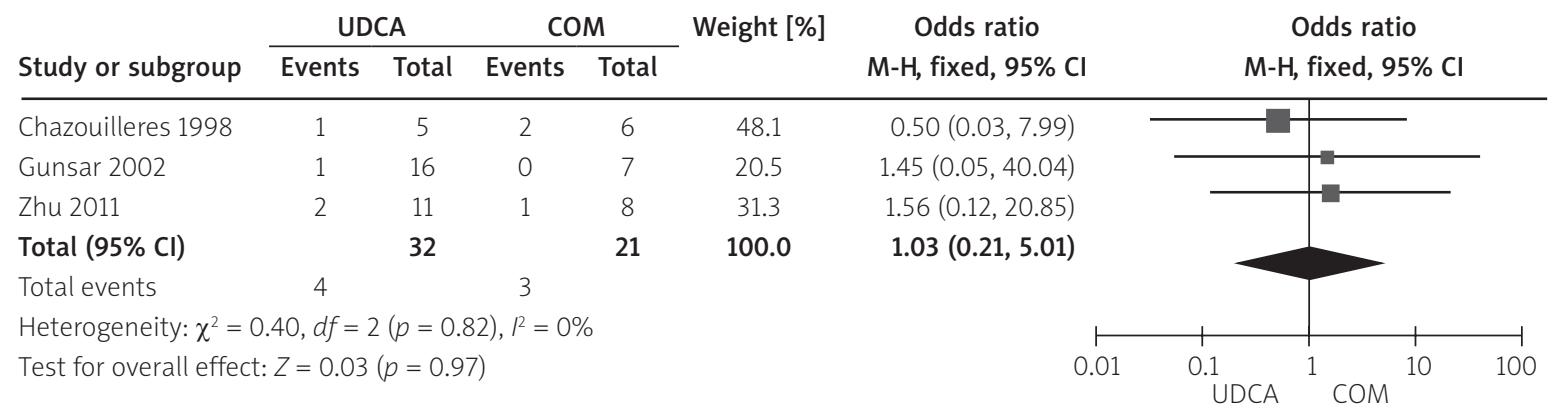

Figure 5. Adverse events in patients treated with monotherapy versus combination therapy for PBC-AlH

characteristics of both $\mathrm{AIH}$ and $\mathrm{PBC}$, most patients tend to receive a combination therapy, which seems to induce better biochemical and histological responses in patients with this disease. In 2009, the EASL guidelines also advised that UDCA therapy should be administered for 3 months, and if the biochemical response is poor, corticosteroids combination therapy can be added [27, 28].

This study has shown that the combination therapy did not differ significantly from the monotherapy in improving fatigue, jaundice, mortality, death/liver transplantation, or adverse events, but was significantly superior to the monotherapy in reducing serum AP, ALT, and other biochemical liver markers. The literature evaluated was biased because too few studies were included, so more high-quality studies are required to confirm the conclusions drawn here. Three of the included RCTs reported adverse events, whereas the other five did not. From the perspective of drug safety, the differences in the rates of adverse events between the combination therapy and the monotherapy were insignificant. It has been suggested that the combination therapy is a relatively safe treatment. In clinical trials, the efficacy of treatments and the adverse reactions should be given equal value.

\section{Conclusions}

We recommend that patients diagnosed with overlap syndrome undertake early treatment that combines UDCA with corticosteroids. This therapy is effective for these patients and can improve their liver biochemical indicators. Although the combination therapy is a relatively safe treatment, adverse effects should be closely monitored when taken at the recommended dose. Because corticosteroids may cause bleeding, fractures, high blood sugar, high blood pressure, high cholesterol, pancytopenia, or severe infections [29-31], PBC-AIH patients require efficient and safe treatment regimens.

\section{Acknowledgments}

Huawei Zhang and Sainan Li contributed equally to this work and should be considered co-first authors.

This study was supported by the National Natural Science Foundation of China (Grant no. 81270515). 

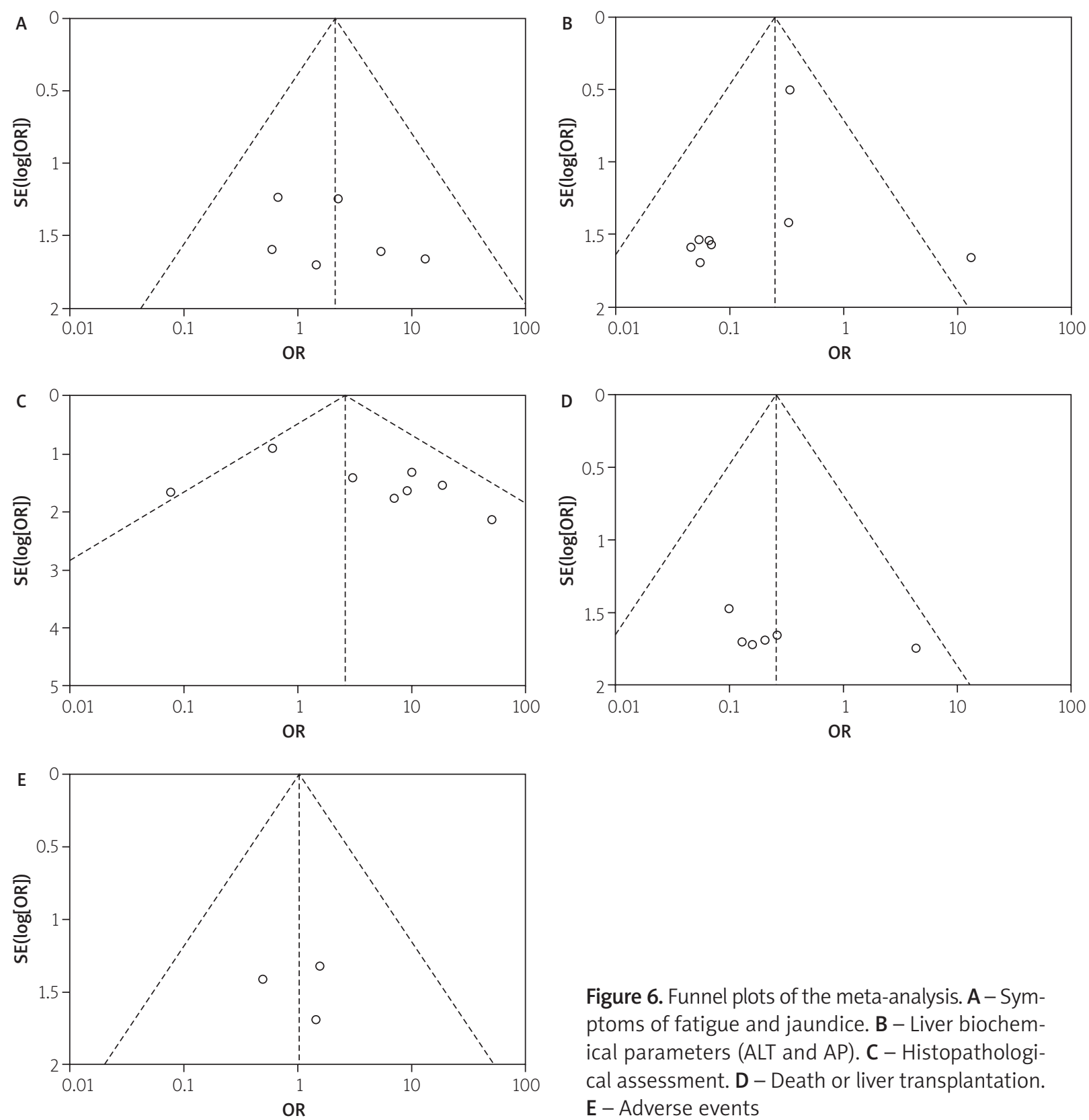

Figure 6. Funnel plots of the meta-analysis. A - Symptoms of fatigue and jaundice. B - Liver biochemical parameters (ALT and AP). C - Histopathological assessment. D - Death or liver transplantation. E - Adverse events

\section{Conflict of interest}

The authors declare no conflict of interests.

\section{References}

1. Czaja AJ. Frequency and nature of the variant syndromes of autoimmune liver disease. Hepatology 1998; 28: 360-5.

2. Rust C, Beuers U. Overlap syndromes among autoimmune liver disease. World J Gastroenterol 2008; 14: 3368-73.

3. Joshl S, Cauch-Dudek K, Wanless IR, et al. Primary biliary cirrhosis with additional features of autoimmune hepatitis: reapprise to therapy with ursodeoxycholic acid. Hepatology 2002; 35: 409-13.

4. Talwalkar JA, Keach JC, Angulo P, et al. Overlap of autoimmune hepatitis and primary biliary cirrhosis: an evaluation of a modified scoring system. Am J Gastroenterol 2002; 97: 1191-7.

5. Neuhauser M, Bjornsson E, Treeprasertsuk S, et al. Autoimmune hepatitis - PBC overlap syndrome: a simplified scoring system May assist in the diagnosis. Am J Gastroenterol 2010; 105: 345-53.

6. Manns MP, Czaja AJ, Gorham JD, et al. Diagnosis and management of autoimmune hepatitis. Hepatology 2010; 51: 2193-213.

7. Bakker GJ, Haan YC, Maillette de Buy Wenniger LJ, et al. Sarcoidosis of the liver: to treat or not to treat? Neth J Med 2012; 70: 349-56. 
8. Delgado JS, Vodonos A, Delgado B, et al. Primary biliary cirrhosis in Southern Israel: a 20-year follow-up study. Eur J Intern Med 2012; 23: e193-8.

9. Muratori P, Granito A, Pappas G, et al. The serological profile of the autoimmune hepatitis/primary biliary cirrhosis overlap syndrome. Am J Gastroenterol 2009; 104: 1420-5.

10. Chazouilleres O, Wendum D, Serfaty L, et al. Long term outcome and response to therapy of primary biliary cirrhosis-autoimmune hepatitis overlap syndrome. J Hepatol 2006; 44: 400-6.

11. Wu CH, Wang $\mathrm{QH}$, Tian GS, et al. Clinical features of the overlap syndrome of autoimmune hepatitis and primary biliary cirrhosis: retrospective study. Chin Med (Engl) 2006; 119: 238-41.

12. Zhang Y, Lu J, Dai W, et al. Combination therapy of ursodeoxycholic acid and corticosteroids for primary biliary cirrhosis with features of autoimmune hepatitis: a meta-analysis. Gastroenterol Res Pract 2013; 2013: 490731

13. Chazouilleres O, Wendum D, Serfaty L, et al. Primary biliary cirrhosis-autoimmunehepatitis overlap syndrome: clinical features and response to therapy. Hepatology 1998; 28: 296-301.

14. Wu D, Wu SM, Lu J, et al. Rifaximin versus nonabsorbable disaccharides for the treatment of hepatic encephalopathy: a meta-analysis. Gastroenterol Res Pract 2013; 2013: 236963.

15. Jadad AR, Moore RA, Carroll D, et al. Assessing the quality of reports of randomized clinical trials: is blinding necessary? Control Clin Trials 1996; 17: 1-12.

16. Kjaergard LL, Villumsen J, Gluud C. Reported methodologic quality and discrepancies between large and small randomized trials in meta-analyses. Annals Intern Med 2001; 135 : 982-9.

17. Chazouilleres O, Wendum D, Serfaty L, et al. Primary biliary cirrhosis-autoimmunehepatitis overlap syndrome: clinical features and response to therapy. Hepatology 1998; 28: 296-301.

18. Gunsar F, Akarca US, Ersoz G, et al. Clinical and biochemical features and therapy responses in primary biliary cirrhosis and primary biliary cirrhosis-autoimmune hepatitis overlap syndrome. Hepatogastroenterology 2002; .49: 1195-200.

19. Heurgue A, Vitry F, Diebold MD, et al. Overlap syndrome of primary biliary cirrhosis and autoimmune hepatitis: a retrospective study of 115 cases of autoimmune liver disease. Gastroenterol Clin Biol 2007; 31; 17-25.

20. Ozaslan E, Efe C, Akbulut S, et al. Therapy response and outcome of overlap syndromes: autoimmune hepatitis and primary biliary cirrhosis compared to autoimmune hepatitis and autoimmune cholangitis. Hepatogastroenterology 2010; 57: 441-6.

21. Tanaka A, Harada K, Ebinuma H. et al. "Primary biliary cirrhosis-autoimmune hepatitis overlap syndrome: a rationale for corticosteroids use based on a nation-wide retrospective study in Japan. Hepatol Res 2011; 41: 877-86.

22. Zhu JY, Shi YQ, Han ZY, et al. Observation on therapeutic alliance with UDCA and glucocorticoids in AlH-PBC overlap syndrome. Zhonghua Gan Zang Bing Za Zhi 2011; 19: 334-9.

23. Ozaslan E, Efe C, Heurgue-Berlot A, et al. Factors associated with response to therapy and outcome of patients with primary biliary cirrhosis with features of autoimmune hepatitis. Clin Gastroenterol Hepatol 2014; 12: 863-9.

24. Manns MP, Czaja AJ, Gorham JD, et al. Diagnosis and management of autoimmune hepatitis. Hepatology 2010; 51: 2193-213.
25. Luxon BA. Diagnosis and treatment of autoimmune hepatitis. Gastroenterol Clin North Am 2008; 37: 461-78.

26. Poupon R, Poupon RE.Treatment of primary biliary cirrhosis. Baillieres Best Pmct Res Clin Gastroenterol 2000; 14: 615-28.

27. Yokokawa J, Saito H, Kanno Y, et al. Overlap of primary biliary cirrhosis and autoimmunehepatitis: characteristics, therapy, and long term outcomes. J Gastroenterol Hepatol 2010; 25: 376-82.

28. Leuschner U. Primary biliary cirrhosis: presentation and diagnosis. Clin Liver Dis 2003; 7: 741-58.

29. Ozaslan E. Autoimmune hepatitis-autoimmune cholangitis overlap syndrome and autoimmune thyroiditis in a patient with celiac disease. Eur J Gastroenterol Hepatol 2009; 21: 716-8.

30. Schulz KF, Chalmers I, Hayes RJ, Altman DG. Empirical evidence of bias. Dimensions of methodological quality associated with estimates of treatment effects in controlled trials. JAMA 1995; 273: 408-12.

31. Boberg KM, Chapman RW, Hirschfield GM. Overlap syndromes: the International Autoimmune Hepatitis Group (IAIHG) position statement on a controversial issue. J Hepatol 2011; 54: $374-85$

Received: 24.11.2014

Accepted: 22.01.2015 